\title{
Metas Parentais de Socialização em Relação ao Desenvolvimento de seus Filhos
}

\author{
Zoraide Margaret Bezerra Lins \\ Nádia Maria Ribeiro Salomão \\ Lucivanda Cavalvante Borges \\ Universidade Federal da Paraíba, João Pessoa, PB, Brasil \\ Samuel Lincoln Bezerra Lins" \\ Terezinha Féres Carneiro \\ Pontifícia Universidade Católica do Rio de Janeiro, Rio de Janeiro, RJ, Brasil
}

\begin{abstract}
RESUMO
O objetivo deste estudo foi analisar as metas de socialização parental com relação ao desenvolvimento de seus filhos. Pretendeu-se, ainda, identificar as estratégias e fontes de ajuda que as mães e os pais buscam para o desenvolvimento dessas metas. Participaram deste estudo 18 homens e 18 mulheres, casados entre si, que tinham apenas um filho. Os resultados mostraram que as metas mais valorizadas por ambos os pais e mães foram o respeito aos outros, honestidade, êxito escolar, êxito pessoal e afetividade. Ao comparar as metas de socialização entre pais e mães, os resultados demonstraram mais semelhanças do que diferenças, verificando-se que os esforços tendem mais a ser no sentido de combinar responsabilidades na busca de uma co-paternidade.
\end{abstract}

Palavras-chave: metas; socialização; mães; pais; interações sociais.

\section{ABSTRACT \\ Parental Socialization Goals With Respect to the Development of Their Children}

The aim of this study was to analyze the goals of parental socialization regarding the development of their children. The aim is also to identify strategies and sources of help that mothers and fathers seek to develop these goals. The study included 18 men and 18 women, married to each other, who had only one child. The results showed that the most valued goals by both fathers and mothers were respect for others, honesty, academic achievement, personal success and affectionateness When comparing the socialization goals between fathers and mothers, the results showed more similarities than differences, verifying that efforts tend to be more towards combining responsibilities in pursuit of a co-parenting.

Keywords: goals; socialization; mothers; fathers; social interactions.

A família, em suas diversas configurações, tem sido um dos principais agentes de socialização da criança, mediando valores, crenças e comportamentos. Para Rogoff (2005), pais, mães e outros cuidadores desempenham um papel particular na socialização da criança, encorajando comportamentos e atitudes que são necessárias à adaptação para conviver em comunida- de. Eles organizam atividades e criam estratégias de cuidado e de educação com o objetivo de coordenar a relação entre as crianças e o mundo físico, as interações das crianças entre si e também com as demais pessoas. Tais estratégias estão relacionadas às crenças e metas de socialização estabelecidas pelos pais para os seus filhos.

\footnotetext{
* Endereço para correspondência: Samuel Lincoln Bezerra Lins - samuel.bezerra.lins@gmail.com
} 
As crenças que os adultos desenvolvem sobre as necessidades, as capacidades e o desenvolvimento da criança guiam as práticas de cuidado infantil (Harkness \& Super, 1996). Porém, é importante salientar que essa relação entre as metas de socialização e as estratégias ou práticas educativas não é direta e causal, pois ocorre de forma bidirecional, através de uma complexa rede de interinfluências dinâmicas e não lineares, entre o indivíduo e o contexto sociocultural (Lightfoot \& Valsiner, 1992).

Algumas pesquisas têm mostrado indicações de que as crenças parentais influenciam as estratégias adotadas pelos pais (Keller, 2007; Kobarg, Sachetti, \& Vieira, 2006; Seidl-de-Moura et al., 2008). Um estudo realizado por Sigel e Kim (1992), sobre o desenvolvimento da competência representacional das crianças, mostrou relações significativas entre as crenças parentais sobre constructos desenvolvimentais e as estratégias educativas utilizadas pelos mesmos. Neste sentido, os pais que acreditavam que as crianças adquiriam conhecimento através de seus próprios pensamentos e atos tendiam mais a utilizar o uso de estratégias de distanciamento para ensinar as crianças; enquanto que, os pais que adotavam estratégias de autoridade e mais didáticas, acreditavam que as crianças aprendiam mais através da instrução direta.

As metas de socialização parentais podem ser compreendidas como os resultados desejáveis pelos pais aos seus filhos, construídas no contexto sociocultural em que a criança se desenvolve e servem como um veículo através do qual os pais traduzem seus valores parentais globais em ações específicas, podendo ser um mecanismo para realizar essas ações (Moinhos, Lordelo, \& Moura, 2007). Ademais, as metas de socialização e as práticas parentais na educação dos filhos variam de acordo com os grupos culturais e as características do contexto em que vivem os pais (Tulviste, 2013).

A esse respeito, Keller (2007) propôs um modelo ecocultural de desenvolvimento infantil que explica os processos psicológicos a partir das demandas ecoculturais e socioeconômicas de uma dada comunidade. Assim, os pais que vivem em culturas individualistas tendem a valorizar mais as metas que enfatizam a independência e autonomia, enquanto pais que vivem em comunidades coletivistas tendem a valorizar mais as metas que enfatizam a harmonia e a interdependência (Keller, 2007). O modelo autônomo/relacional, que enfatiza a autonomia do self no que se refere à ação e o self relacional no que se refere à proximidade interpessoal, seria mais característico de famílias de classe média, urbana e com nível de escolarização elevado, em sociedades tradicionalmente interdependentes.

No entanto, embora as metas de socialização sejam influenciadas por modelos culturais amplos, como a independência, interdependência e autonomia/relação, elas podem diferenciar-se dentro de uma mesma cultura, ou seja, nem todas as famílias que vivem em uma mesma comunidade apresentam as mesmas metas de socialização para seus filhos. As características da criança, tais como o temperamento, o gênero, e a percepção do papel parental desempenhado por seus pais em sua educação, também influenciam comportamento da criança e as metas de socialização dos próprios pais (Raj \& Raval, 2012). Assim, tanto o desenvolvimento infantil afeta os processos de socialização como os contextos de socialização afetam o desenvolvimento da criança, através das metas parentais.

Um fator de influência importante nas metas de socialização infantil é o sexo dos pais (Cassano, Zeman, \& Sanders, 2014), pois o comportamento parental pode ser alterado nos diferentes contextos familiares, considerando que a presença do cônjuge altera claramente o contexto interativo entre a criança e o outro genitor, transformando a díade em um complexo sistema familiar que inclui o subsistema conjugal e o parental. A importância da inclusão dos pais nos estudos sobre o desenvolvimento infantil deve-se principalmente às mudanças contemporâneas ocorridas no exercício do papel parental, em que este tornou-se mais participativo nos cuidados e interação com as crianças, exercendo uma coparentalidade. Vieira et al. (2013) definem a coparentalidade como o envolvimento mútuo dos pais na educação e decisões sobre a vida dos filhos, apoiando um ao outro no desempenho do papel parental e administração do lar.

No entanto, apesar dessas mudanças contemporâneas no exercício da parentalidade, os resultados de uma revisão sistemática realizada por Vieira et al. (2014) sobre essa temática mostraram que a responsabilidade pela criação dos filhos ainda é atribuída, sobretudo, às mães. Esses autores explicam que o exercício da parentalidade está passando por uma transição entre o reconhecimento da importância da participação do pai no desenvolvimento da criança e a ma- 
nutenção de papéis tradicionais do pai como ajudante da mãe nos cuidados e educação do filho.

Borsa e Nunes (2011) ressaltam que as diferentes relações parentais resultam em diferentes formas de perceber e compreender os filhos. Desse modo, considera-se que as mudanças contemporâneas no exercício da parentalidade também podem repercutir nas metas e estratégias de socialização que pais e mães traçam para seus filhos e que estas, por sua vez, estão interrelacionadas às características do contexto sociocultural em que o indivíduo está inserido.

Pesquisas no contexto brasileiro (Macarini, Martins, Sachetti, \& Vieira, 2010; Moinhos, Lordelo, \& Moura, 2007) têm abordado as metas de socialização através da figura materna. Em relação à figura do pai, Vieira et al. (2014) consideram que há uma escassez de estudos que investiguem quais aspectos do desenvolvimento infantil são influenciados por esse cogenitor. Desse modo, é importante entender a parentalidade como uma unidade de estudo das interações entre mãe, pai e filhos.

Diante do exposto, o presente trabalho teve como objetivo analisar as metas de socialização parental relacionadas aos seus filhos. Além disso, pretendeu identificar as estratégias e fontes de ajuda que as mães e os pais buscam para o desenvolvimento dessas metas.

\section{MÉTODO}

Essa pesquisa caracterizou-se por um estudo descritivo-exploratório e de natureza qualitativa, uma vez que buscou caracterizar e compreender as metas de socialização de pais e mães em relação aos seus filhos.

\section{Participantes}

Participaram deste estudo 18 homens e 18 mulheres casados entre si, que tinham apenas um filho, sendo 9 meninos e 9 meninas, residentes na cidade de João Pessoa/PB, composta por critério de conveniência. A idade das mães variou entre 18 e 41 anos e a dos pais entre 23 e 54 anos. O nível de escolaridade das mães variou desde o ensino fundamental incompleto até o nível de pós-graduação. Elas apresentaram um nível de escolaridade mais alto em relação aos pais, $61.11 \%$ têm ou estão cursando o nível superior, e a maior parte delas trabalha fora do lar. Em relação aos pais, 33.33\% encontram-se cursando ou já têm o nível superior completo. A renda familiar variou entre 1 a 12 salários mínimos. Em relação à religião, $55.56 \%$ das mães declararam serem católicas, $27.78 \%$ evangélicas, $11.11 \%$ espíritas e $5.56 \%$ testemunhas de Jeová. A religião dos pais foi praticamente a mesma das mães, apenas um casal não tinha a mesma religião, a mãe é evangélica e o pai, católico (ver Tabela $1)$.

Tabela 1

Distribuição dos Participantes Segundo a Religião

\begin{tabular}{ccccccc} 
Religião & \multicolumn{2}{c}{ Mães } & \multicolumn{2}{c}{ Pais } & \multicolumn{2}{c}{ Total } \\
& $f$ & $\%$ & $f$ & $\%$ & $f$ & $\%$ \\
\hline Católica & 10 & 55,56 & 11 & 61,11 & 21 & 58,33 \\
Evangélica & 5 & 27,78 & 4 & 22,22 & 9 & 25,00 \\
Espírita & 2 & 11,11 & 2 & 11,11 & 4 & 11,11 \\
Testemunhas de Jeová & 1 & 5,56 & 1 & 5,56 & 2 & 5,56 \\
\hline Total & 18 & 100 & 77 & 18 & 36 & 100 \\
\hline
\end{tabular}

O estudo foi realizado com famílias nucleares e o recorte foi feito de forma que englobasse casais que tivessem filhos com a idade de 12 a 48 meses, sendo esta, uma faixa etária fundamental do desenvolvimento humano quando ocorre um intenso processo de socialização parental. A idade média das crianças foi de 28 meses.

\section{Instrumentos}

Para coleta dos dados foram utilizados um questionário sociodemográfico sobre a caracterização dos participantes, como idade, escolaridade, profissão, estado civil, religião, número de filhos e renda familiar. Para conhecer as metas de socialização, assim como as estratégias e fontes de ajuda para o desenvol- 
vimento dessas, foi utilizado um roteiro de entrevista semiestruturada com cinco perguntas desenvolvidas a partir da literatura e dos objetivos do estudo.

\section{Procedimentos}

O projeto de pesquisa foi submetido e aprovado pelo Comitê de Ética e Pesquisa do Hospital Universitário Lauro Wanderley da Universidade Federal da Paraíba ( $\left.n^{\circ} 363 / 09\right)$. A coleta de dados foi realizada no domicílio dos casais participantes, mediante apresentação de uma carta explicativa sobre a pesquisa e seus objetivos, e a assinatura de um Termo de Consentimento Livre e Esclarecido. Cada entrevista foi realizada individualmente com 18 mães e com 18 pais, totalizando 36 entrevistas. Cada cônjuge foi entrevistado individualmente e nenhum deles teve acesso às respostas do outro.

As entrevistas foram gravadas em áudio, transcritas e analisadas segundo a técnica de análise de conteúdo de Bardin (2007). A identificação das categorias de análise deste estudo foi realizada a partir da pré-análise, exploração do material e interpretação dos resultados, considerando-se a classe temática metas de socialização parental, e responderam aos critérios de exaustividade, representatividade, homogeneidade e pertinência. Os resultados foram discutidos com base em autores internacionais e nacionais da psicologia do desenvolvimento infantil (ex. Bronfenbrenner \& Morris, 1998; Keller, 2007; Vieira et al., 2014; Vieira et al., 2013).

\section{RESULTADOS E DISCUSSÃO}

Das falas das mães e dos pais, emergiram cinco categorias de análise: (1) qualidades que os pais esperam para seus filhos; (2) expectativas sobre o alcance das metas de socialização parental; (3) procedimentos para o alcance das metas de socialização parental, (4) organização da rotina diária da criança e, (5) fontes de ajuda para orientação na educação do filho. A seguir, serão apresentadas as categorias com as suas respectivas subcategorias.

\section{Qualidades que os pais esperam para seus filhos}

No que se refere à primeira categoria qualidades que os pais esperam para seus filhos, observou-se que houve um equilíbrio entre as cinco subcategorias emergidas, tanto nos relatos das mães como nos relatos dos pais (ver Tabela 2).

Tabela 2

Distribuição Percentual da Categoria 'Qualidades que os Pais Esperam para Seus Filhos'

\begin{tabular}{cccccccc} 
Subcategorias & \multicolumn{2}{c}{ Mães } & \multicolumn{2}{c}{ Pais } & \multicolumn{2}{c}{ Total } \\
& $f$ & $\%$ & $f$ & $\%$ & $f$ & $\%$ \\
\hline Respeito aos outros, à família e a Deus & 24 & 29.63 & 17 & 22.08 & 41 & 25.95 \\
Honestidade & 18 & 22.22 & 23 & 29.87 & 41 & 25.95 \\
Êxito escolar & 17 & 20.99 & 13 & 16.88 & 30 & 18.99 \\
Êxito pessoal & 12 & 14.81 & 12 & 15.59 & 24 & 15.19 \\
Afetividade & 10 & 12.35 & 12 & 15.58 & 22 & 13.92 \\
\hline Total & 81 & 100 & 77 & 100 & 158 & 100 \\
\hline
\end{tabular}

Como mostra a Tabela 2, tanto os pais como as mães relataram que esperam que seus filhos desenvolvam qualidades como: o respeito aos outros, a honestidade, o êxito escolar e pessoal, e a afetividade. Para as mães o respeito aos outros apresentou um percentual maior $(29.63 \%)$, seguido da honestidade (22.02\%), já para os pais, a honestidade (29.87\%) apresentou um percentual maior, seguido do respeito aos outros
(22.08\%). Como mostrado nas falas dos pais e das mães, a seguir:

Que ele tenha respeito com as pessoas / humano acima de tudo, com capacidade de valorizar o ser humano, que saiba respeitar o próximo/ temente à Deus, que saiba respeitar os pais / ser fiel aos propósitos de Deus (mães) 
Bem acho que honestidade, que é o principal, que seja uma pessoa, honesta, porque creio que ela sendo uma pessoa honesta as outras qualidades virão / boa pagadeira [sic], econômica/que frequenta a igreja, que lê a Bíblia e pratique [pais].

As metas de socialização dos filhos priorizadas pelos pais nesta pesquisa apresentaram-se relacionadas ao modelo interdependente das trajetórias do desenvolvimento humano (Keller, 2007), haja vista a valorização dos papeis sociais como o bom comportamento da criança e adequação às expectativas da sociedade, assim como a afetividade nas relações interpessoais. Observou-se, também, a valorização de metas de socialização voltadas para a autonomia e independência da criança, como a obtenção do êxito escolar e pessoal, o que pode indicar uma integração do modelo autônomo e relacional, em que o self é autônomo quanto às suas ações e relacional quanto à proximidade nas relações intergrupais.

Pesquisas no contexto brasileiro (Vieira et al., 2014) têm mostrado a valorização de metas de socialização paterna em relação aos filhos voltadas para a autossuficiência, independência, sucesso profissional, honestidade frente à família e à sociedade. Em relação à figura materna, Piovanotti (2007) também mostrou a priorização de metas de socialização caracterizadas como autônomo-relacional.

É importante considerar as características sociodemográficas dos participantes na análise das metas de socialização por eles priorizadas nesse estudo. Todos os participantes são religiosos, com uma certa predominância da religião católica e evangélica, o que pode explicar a valorização de metas orientadas para as relações intergrupais e de cunho religioso, como o respeito aos outros, à família e à Deus. Desse modo, tais resultados precisam ser relativizados, pois a denominação religiosa tem influência nas metas de socialização que os pais desejam para os filhos, embora essa relação não seja direta, uma vez que as características dos pais e da criança, assim como do contexto cultural maior, estão inter-relacionadas nos processos de construção dessas metas.

Em relação ao sexo dos pais, apesar de uma pequena diferença na prioridade das qualidades apresentadas pelos pais aos seus filhos, tais resultados apontaram para expectativas semelhantes entre ambos progenitores. Os estudos realizados por Bandeira, Moura e Vieira (2009) corroboram com esses resultados, onde as mães e os pais também enfatizam em suas metas, aspectos mais relacionados às expectativas sociais e o autoaperfeiçoamento.

\section{Procedimentos para alcançar as metas parentais de socialização}

Da segunda categoria, foram extraídas cinco subcategorias, apresentadas na Tabela 3.

Tabela 3

Distribuição Percentual da Categoria 'Procedimentos para Alcançar as Metas Parentais de Socialização'.

\begin{tabular}{ccccccc}
\hline Subcategorias & \multicolumn{2}{c}{ Mães } & \multicolumn{2}{c}{ Pais } & \multicolumn{2}{c}{ Total } \\
\hline Ensinar a discernir entre o certo e o errado & $f$ & $\%$ & $f$ & $\%$ & $f$ \\
Ensinar a respeitar as pessoas & 18 & 36.73 & 12 & 44.45 & 30 & 39.47 \\
Ensinar a ter responsabilidade & 10 & 20.41 & 2 & 7.41 & 12 & 15.79 \\
Dar o exemplo & 9 & 18.37 & - & - & 9 & 11.84 \\
Fazer coisas boas com ele & 7 & 14.29 & 8 & 29.64 & 15 & 19.74 \\
Participar no lazer & 5 & 10.20 & - & - & 5 & 6.58 \\
Procedimento não referido & - & - & 3 & 11.11 & 3 & 3.95 \\
Total & - & - & 2 & 7.41 & 2 & 2.63 \\
\hline
\end{tabular}

Observou-se que os procedimentos mais utilizados pelas mães para alcançar as metas de socialização foram: ensinar a discernir entre o certo e o errado
(36.73\%), ensinar a respeitar as pessoas $(20.41 \%)$ e ensinar a ter responsabilidades (18.37\%), dar o exemplo (14.29\%) e fazer coisas boas com ele (10.20\%). 
Em relação aos pais, as principais subcategorias foram: Ensinar a discernir entre o certo e o errado $(44.45 \%)$ e dar o exemplo (29.64\%), como mostram os relatos a seguir:

Sempre procuro ensinar o caminho certo e corrigilo, não deixo à toa [...] estou atenta nas brincadeiras [...] oh, isto não é bom, e ela vai tendo noção do que é certo e o que é errado/ensino a diferenciar o que é sim e o que é não / vou ensinando pouco a pouco, porque ela é muito pequena. [mães]

Eu procuro mostrar no dia a dia o que é certo e o que é errado/ ensino, educo no caminho que deve seguir/ reclamo e disciplino quando faz coisas erradas, mas lá na frente ele vai entender. [pais]

As mães foram as que referiram mais procedimentos para alcançar as metas de socialização. Esse resultado corrobora os achados da revisão sistemática de Vieira et al. (2014) os quais mostraram que apesar das mudanças contemporâneas no papel parental, a mãe ainda é a principal responsável pelos cuidados e educação dos filhos. No entanto, não é meramente a igualdade de distribuição de tarefas na educação do filho o que se espera da atuação do pai, mas, sobretu- do, o exercício conjunto das funções parentais, superando o papel tradicional da figura paterna como o provedor da casa e a mulher como cuidadora dos filhos.

Apesar das mães terem expressado um percentual mais elevado de estratégias para o alcance das metas, os pais também se apresentaram como responsáveis nesse processo. Assim, esses resultados são congruentes com as considerações de Vieira et al. (2013) sobre as mudanças do modelo tradicional no exercício da parentalidade em direção ao envolvimento mútuo dos pais na educação dos filhos, correspondendo à coparentalidade.

\section{Organização da rotina diária da criança}

A terceira categoria organização da rotina diária da criança foi subdividida em rotina sistemática e rotina não sistemática, tanto para os pais como para as mães (ver Tabela 4). O termo rotina sistemática significa que os pais organizam sistematicamente o cotidiano da criança, estabelecendo horários para as atividades a serem realizadas. O termo rotina não sistemática significa que os pais não organizam sistematicamente o cotidiano da criança, ou seja, não há horários estabelecidos para determinadas atividades.

Tabela 4

\begin{tabular}{ccccccccc} 
Distribuição Percentual da Categoria 'Organização da Rotina Diária da Criança' \\
\hline Subcategorias & \multicolumn{2}{c}{ Mães } & \multicolumn{2}{c}{ Pais } & \multicolumn{2}{c}{ Total } \\
& $f$ & $\%$ & $f$ & $\%$ & $f$ & $\%$ \\
Rotina sistemática & 12 & 66.67 & 5 & 27.78 & 17 & 47.22 \\
Rotina não sistemática & 6 & 33.33 & 13 & 72.22 & 19 & 52.78 \\
\hline Total & 18 & 100 & 18 & 100 & 36 & 100 \\
\hline
\end{tabular}

De acordo com a Tabela 4, a organização sistemática da rotina da criança foi a mais apresentada nos relatos das mães $(66.67 \%)$ do que dos pais $(27.78 \%)$. Assim como na categoria estratégias de socialização, a participação da mãe no cuidado e educação da criança apresentou um percentual maior em relação à figura paterna. Ainda que a maioria das mães estudadas trabalhe fora do lar, estas são as principais responsáveis pela organização da rotina diária de seus filhos, seja orientando um cuidador na sua ausência, seja no momento em que está em casa. De acordo com Fonseca e
Salomão (2006) e Diniz e Salomão (2010) a mãe interage mais no atendimento das necessidades básicas do filho, e o pai tende mais do que a mãe, a se engajar em atividades esportivas, de lazer e a dramatizar histórias. As falas dos pais e das mães a seguir ilustram esse resultado:

Ensino a ter horários, hora de assistir à TV, hora de fazer as tarefas da escolinhal procuro incentivar bastante para ele ir criando responsabilidade desde pequeno. [mães] 
Só quero o melhor para ela, a gente se diverte, passeio e brinco no parquel a gente tenta educar, na parte do esporte, passeio e lazer, ensino a cantar e a tocar violão. (pais)

Outras investigações, com mães e pais, também ressaltam as diferenças na interação mãe-filho e paifilho (Belsky, Gilstrap, \& Rovine, 1984; Brazelton \& Cramer, 1992; Kochanska \& Kim, 2014; Krob, 1999; Parke, 1996; Piccinini, Frizzo, \& Marin, 2007; Wilson \& Durbin, 2013). Quanto às atividades comumente realizadas com a criança, as mães parecem passar mais tempo envolvidas com os cuidados pessoais e de higiene da criança, como o banho e a alimentação, enquanto os pais tendem a usar mais o seu tempo em atividades de lazer, brincando com a criança.

As interações mãe-bebê e pai-bebê são diferentes uma da outra, a criança consegue desde muito cedo distinguir o parceiro adulto, e espera da mãe e do pai um determinado padrão de resposta. Nas interações com a mãe e com o pai, a criança aprende sobre a diferenciação e a sincronização de comportamentos com cada um deles, da mesma forma que estes também aprendem com a criança (Brazelton \& Cramer, 1992). Além disso, o fato de a criança responder diferentemente ao pai e à mãe, permite aos genitores que se sintam importantes e ressignifiquem seus papéis. Desse modo, o estudo da dinâmica interativa deve incluir a forma como as mães e os pais estimulam a criança. $\mathrm{O}$ excesso ou a falta de estimulação, o tipo de reciprocidade e sincronia estabelecida, e a forma como os genitores negociam diante das dificuldades e dos conflitos permitem uma transformação na interação mãe-pai-filho. Embora as interações possam ser qualitativamente diferentes, o mais importante é que o pai e a mãe sejam responsivos e sensíveis à criança. Como cuidadores competentes devem aprender a reagir apropriadamente às mensagens da criança, comportando-se responsivamente, mesmo que a resposta de um ou de outro genitor seja diferente, contanto que seja adequada ao contexto da interação.

\section{Fontes de ajuda para orientação na educação da criança}

Essa categoria refere-se às fontes de ajuda que os pais buscam como apoio na educação dos filhos. A partir dos relatos dos pais foram encontradas seis subcategorias: pais e/ou esposo(a), própria vivência, leitura e/ou internet, Deus/Bíblia, pediatras/profissionais e pessoas experientes (ver Tabela 5).

Tabela 5

Distribuição Percentual da Categoria 'Fontes de Ajuda para Orientação na Educação da Criança'

\begin{tabular}{cccccccc} 
Subcategorias & \multicolumn{2}{c}{ Mães } & \multicolumn{2}{c}{ Pais } & \multicolumn{2}{c}{ Total } \\
& $f$ & $\%$ & $f$ & $\%$ & $f$ & $\%$ \\
Pais e /ou esposas & 19 & 41.30 & 22 & 42.30 & 41 & 41.84 \\
Própria vivência & 11 & 23.90 & 12 & 23.10 & 23 & 23.47 \\
Leitura e /ou internet & 9 & 19.60 & 6 & 11.50 & 15 & 15.31 \\
Deus e /ou Bíblia & 5 & 10.90 & 8 & 15.40 & 13 & 13.27 \\
Pediatras/profissionais e pessoas experientes & 2 & 4.30 & 4 & 7.70 & 6 & 6.11 \\
\hline Total & 46 & 100 & 52 & 100 & 98 & 100 \\
\hline
\end{tabular}

A Tabela 5 mostra que tanto para as mães como para os pais, a subcategoria 'pais e/ou esposo(a)' destacou-se como principal fonte de ajuda, com $41.30 \%$ para as mães e $42.30 \%$ para os pais, seguido da subcategoria 'própria vivência', com $23.90 \%$ para as mães e $23.10 \%$ para os pais. Verificou-se que os entrevistados citaram seus pais como exemplos a serem seguidos, onde se respaldam para a criação dos filhos, ape- sar de destacar que o tempo atual é bem diferente da época e da criação que receberam dos seus genitores. Entretanto, ressalta-se que o papel do pai na educação dos filhos na contemporaneidade apresenta grandes mudanças em relação a épocas passadas, considerando-se, entre outros fatores, as mudanças nas configurações familiares, o que trouxe implicações para os 
papeis parentais e, consequentemente, afetaram as relações pais e filhos.

Outra fonte de ajuda foi o cônjuge e os pais do mesmo, pois assumem que seu cônjuge também recebeu dos seus genitores e do seu contexto valores e ensinamentos que são importantes e que estão sendo transmitidos na sua prática educativa para com seus filhos, como pode-se ver nas falas a seguir.

Com os pais / o exemplo do pai e da mãe é fundamental /com outros pais para ganhar experiência, $e$ com meu marido/a pessoa que procuro ajuda é minha sogra / foi um pouco dos meus pais os erros e os acertos / muito conselho da minha avó. (mães)

Bom eu tenho o exemplo dos meus pais, de uma boa educação que nossos pais nos deram [...] o fundamental é ter uma base, é ter um alicerce, como nossos pais nos criaram / além de conversar com a minha esposa, escuto orientação dos meus pais / com a minha esposa aprendi algumas coisas e a gente vai juntando, com o que ela sabia e eu sabia / com valores de nossos pais mesmo, eu aprendi com meus pais, pela criação que minha mãe me deu. (pais)

As crenças apresentadas nas falas maternas e paternas revelaram que existe uma relação entre as circunstâncias de suas vidas no momento atual, o modo pelo qual foram criados por seus pais, bem como as suas experiências de vida e o contexto cultural inserido, ou seja, há uma influência mútua entre culturas, práticas, e vivências pessoais. Entretanto, é preciso considerar que, embora cada pessoa seja influenciada por um sistema cultural de crenças e práticas, o indivíduo não é apenas um mero receptáculo para a transmissão cultural, suas experiências individuais e com seu grupo social contribuem para recriação dessas crenças e práticas (Lordelo, Fonseca, \& Araújo, 2000, Valsiner, 2007).

Desse modo, pode-se considerar o papel do ambiente como um conjunto de atributos materiais e sociais com os quais o indivíduo interage (Brofenbrenner $\&$ Morris, 1998). A análise dos resultados da presente pesquisa corrobora com esta afirmação, quando se verifica que os entrevistados, mesmo referindo seus pais como a principal fonte de ajuda, também referiram, em segundo lugar, a própria vivência, como exemplificado nas falas a seguir:

Aprendi a cuidar do meu filho, porque já tinha uma experiência, já cuidava de meu sobrinho/tento trazer as coisas boas da minha família / foi no dia a dia mesmo [...] eи e meu marido aprendendo com a vida. (mães)

A ajuda vem basicamente de conhecimentos gerais da vidala gente aprendeu só mesmo / nossa própria vivencia de vida / com conceitos que eu já tinha / foi sozinho mesmo. (pais)

Para complementar a necessidade de adquirir informações, as mães e os pais ainda referiram outras fontes de ajuda, que julgaram importantes para receber novos conhecimentos e se atualizarem sobre o modo de criar e educar seus filhos, a saber: leituras e/ou internet, pediatras/profissionais e pessoas experientes. Isso indica que existe uma busca para o aprimoramento da educação de seus filhos. Também foi mencionada uma subcategoria (Deus e/ou Bíblia) relacionada à transmissão da vida religiosa, que segundo Caldana (1998), sempre foi bastante presente na educação das crianças. Estes resultados corroboram com os estudos de Szejer e Stewart (1997) quando relatam que, embora o modo como os pais foram criados seja fundamental para construção de seus ideais de maternidade e paternidade, não é suficiente para mostrar-lhes como ser mãe e pai no momento de educar seus próprios filhos.

\section{Expectativas sobre 0 alcance das metas de sociali- zação parental}

Essa categoria se subdividiu em três subcategorias, para ambos os pais e mães: Expectativa positiva, dúvida e certeza (ver Tabela 6 ). 
Tabela 6

\begin{tabular}{|c|c|c|c|c|c|c|}
\hline \multirow{2}{*}{ Subcategorias } & \multicolumn{2}{|c|}{ Mães } & \multicolumn{2}{|c|}{ Pais } & \multicolumn{2}{|c|}{ Total } \\
\hline & $f$ & $\%$ & $f$ & $\%$ & $f$ & $\%$ \\
\hline Expectativa positiva & 22 & 43.14 & 15 & 38.46 & 37 & 41.11 \\
\hline Dúvida & 21 & 41.18 & 17 & 43.59 & 38 & 42.22 \\
\hline Certeza & 8 & 15.68 & 7 & 17.95 & 15 & 16.67 \\
\hline Total & 51 & 100 & 39 & 100 & 90 & 100 \\
\hline
\end{tabular}

Os resultados da Tabela 5 mostram que $43.14 \%$ das mães e $38.46 \%$ dos pais relataram que esperam alcançar as metas de socialização planejadas para seus filhos. Por outro lado, $41.18 \%$ das mães e $43.59 \%$ dos pais relataram apresentar dúvidas no alcance das expectativas de socialização para seus filhos.

Mas os pais não podem ter tanta certeza se vão conseguir ou não seus objetivos em relação a suas metas parentais, devido a vários aspectos, como as primeiras trocas interacionais, os cuidados básicos oferecidos, as ações e reações entre a criança e o meio ambiente, que influenciam o desenvolvimento do indivíduo (Regen, Cortez, \& Ardore, 2001). Essas vivências sendo positivas ou negativas, serão posteriormente transferidas ao meio social mais amplo, permitindo ou não a sua adaptação. Cada filho tem suas características e reações individuais próprias, e com cada um se estabelece diferentes tipos de relação. Além das características da criança, é preciso considerar as características dos pais e mães e do contexto sociocultural mais amplo. Como afirmam Raj e Raval (2012), a percepção do papel parental desempenhado pelos pais na educação dos filhos, também influenciam as metas de socialização.

Desse modo observou-se que os participantes relataram, predominantemente, expectativas positivas e dúvidas, a respeito de suas expectativas sobre o alcance de suas metas parentais para com seus filhos, como se pode observar nos recortes das falas a seguir:

Eu espero que ele seja assim como eu estou pensando / eu acho, pelo menos eu espero, a gente almeja, espero que ele consiga / ah! eu não sei não, hoje em dia está difícil, nunca sabe se vai dar certo, porque a gente ensina, mas cada ser humano reage de um jeito. (mães)
Eu espero que sim, desejo que sim [...] a gente tem que almejar, colocar na cabeça e fazer uma meta / eu não sei, mas eu queria que sim / vou tentar, mas isso só o tempo vai dizer [...] quem vai desenvolver é ele, a gente apenas conduz. (pais)

A dúvida expressa pelos pais na realização das metas de socialização dos filhos também pode ser explicada pelo fato de que não se sabe, com clareza, o que corresponde aos valores que os filhos vão demonstrar durante o seu desenvolvimento, mediante as interações com outros grupos sociais além da família, pois a socialização na infância se dá através da bidirecionalidade e não de forma estática e passiva. A criança que está sendo socializada tem suas próprias características e interage com o seu meio social ao mesmo tempo em que sofre influências dele, num processo contínuo de trocas e descobertas. Portanto, considera-se que, no processo de socialização, os pais muitas vezes influenciam o comportamento de seus filhos de forma sutil e indireta, embasados em suas crenças, que poderão, ou não, refletirem nas expectativas sobre o comportamento e a personalidade da criança, influenciando suas ações e atitudes (Bronfenbrenner, 1996).

\section{CONSIDERAÇÕES FINAIS}

O principal objetivo desse trabalho foi analisar as metas de socialização de pais e mães em relação aos seus filhos. Os resultados mostraram a valorização de metas de socialização autônomo relacional, embora as metas voltadas ao atendimento de expectativas sociais tenham apresentado um percentual elevado. Ao analisar as estratégias e rotina de cuidado diário dos filhos, observou-se que apesar das pesquisas mostrarem uma maior participação do pai na educação dos filhos, a 
mãe ainda se apresenta como a principal cuidadora, mesmo exercendo atividades fora de casa.

Contudo, observou-se nesta pesquisa que os pais, em sua maioria, estão interessados em participar do cotidiano, do crescimento dos seus filhos e em envolver-se no cuidado da rotina diária. Em relação às expectativas dos pais e mães sobre a realização das metas de socialização esperadas para os filhos, ressalta-se que o desenvolvimento das metas não depende apenas dos pais, mas da inter-relação com as características dos pais, da criança e do contexto sociocultural em que eles se encontram.

Verificou-se, também, os esforços dos progenitores no sentido de combinar responsabilidades em relação a seus filhos na busca de uma copaternidade. As diferenças entre a mãe e o pai podem ser consideradas como complementares, pois o que se percebeu nas falas dos entrevistados foi que tanto as mães como os pais estavam mais voltados e comprometidos com a responsabilidade de educar e cuidar dos seus filhos, numa construção social do atual contexto histórico.

É importante ressaltar que os resultados aqui encontrados devem ser analisados a partir das características sociodemográficas dos participantes, como a religião, a escolaridade, e a renda familiar, que podem ter influenciado as metas de socialização dos pais em relação aos seus filhos. Considera-se que a maternidade e a paternidade só poderão ser melhor compreendidas a partir de uma análise mais aprofundada das interações familiares e das interações que o grupo familiar estabelece com o grupo social ao qual pertence, considerando as trocas e os processos mais amplos que ocorrem na sociedade.

Assim, sugere-se a realização de estudos que permitam fazer um acompanhamento longitudinal, buscando averiguar as modificações das trocas interacionais que ocorrem com as transições ecológicas da família. Ademais, estudos sobre as metas de socialização infantil, apresentadas por pais e mães em outros contextos de desenvolvimento, como o meio rural, tornam-se necessários para a compreensão da diversidade das interações pais e filhos.

Espera-se que os resultados dessa pesquisa possam contribuir para os profissionais da área da psicologia, educação, e saúde, bem como para todos que trabalham direta e indiretamente com mães, pais e família, tendo em vista a influência das metas de socialização parentais sobre o desenvolvimento da criança.

\section{REFERÊNCIAS}

Bandeira, T., Moura, M., \& Vieira, M. (2009). Metas de socialização de pais e mães para seus filhos. Revista Brasileira Crescimento Desenvolvimento Humano,19 (3), 445-456.

Bardin, L. (2007). Análise de conteúdo. ( $3^{\mathrm{a}}$ ed.). Lisboa: Edições 70.

Belsky, J., Gilstrap, B., \& Rovine, M. (1984). The Pennsylvania infant and family development project, I: Stability and change in mother-infant and father-infant interaction in a family setting at one, three and nine months. Child Development, 55, 692-705.

Bentley, K., \& Fox, R. (1991) Mother and fathers of young children: Comparison of parenting styles. Psychology Report, 69, 320-322.

Braz, M., Dessen, M., \& Silva, N. (2005). Relações conjugais e parentais: uma comparação entre famílias de classes sociais baixa e média. Psicologia: Reflexão e Crítica, 18(2), 151-161.

Borsa, J., \& Nunes, J. (2011). Aspectos psicossociais da parentalidade: O papel de homens e mulheres na família nuclear. Psicologia Argumento, 29(64), 31-39.

Brazelton, T., \& Cramer, B. (1992). As primeiras relações. Tradução de M. B. Cipolla. São Paulo: Martins Fontes.

Bronfenbrenner, U. (1996). A ecologia do desenvolvimento humano: Experimentos naturais e planejados. Porto Alegre: Artes Médicas. (Original publicado em 1979).

Bronfenbrenner, U., \& Morris, P. (1998). The ecology of developmental processes. In: R. M. Lerner \& W. Damon (Eds.), Handbook of child psychology, v. 1 (pp. 9931027). New York: John Wiley \& Sons.

Caldana, R. (1998). A criança e sua educação na família no início do século: autoridade, limites e cotidiano. Temas em Psicologia, 6(2), 87-103.

Cassano, M., Zeman, J., \& Sanders, W. (2014). Responses to children's sadness: Mothers' and fathers' unique contributions and perceptions. Merrill-Palmer Quarterly, 60 (1), 1-23.

Diniz, P., \& Salomão, N. (2010). Metas de socialização e estratégias de ação paternas e maternas. Paidéia, 20(46), 145-154.

Fonseca, P., \& Salomão, N. (2006). Contingência semântica das falas materna e paterna: uma análise comparativa. Psicologia: Reflexão e Crítica, 19(1), 91-97.

Harkness, S., \& Super, C. (1996). Introduction. In: S. Harkness \& C. M Super (Eds.), Parents' Cultural Belief Systems: their origins, expressions, and consequences (pp. 1-23). New York: The Guilford Press.

Keller, H. (2007). Cultures of infancy. Mahwah: Lawrence Eribaum Associates. 
Kobarg, A., Sachetti, V., \& Vieira, M. (2006). Valores e crenças parentais: reflexões teóricas. Revista Brasileira de Crescimento e Desenvolvimento Humano, 16(2), 96102.

Kochanska, G., \& Kim, S. (2014). A complex interplay among the parent-child relationship, effortful control, and internalized, rule-compatible conduct in young children: Evidence from two studies. Developmental Psychology, 50(1), 8-21.

Krob, A. (1999). A transição para a paternidade e a interação pai bebê. Dissertação de Mestrado não publicada, Curso de Pós-Graduação em Psicologia do Desenvolvimento, Universidade Federal do Rio Grande do Sul. Porto Alegre.

Lamb, M. (1997). Fathers and child development: an introductory overview and guide. In: M. Lamb (Eds.), The role of the father in child development (pp. 309-313). New York: $3^{\mathrm{a}}$ ed. John Wiley \& Sons.

Lamb, M. (1999). Parental behavior, family processes, and child development in nontraditional and traditionally understudied families. In M. Lamb (Eds.), Parenting and child development in "nontraditional" families. New Jersey: Lawrence Erlbaum Associates.

Lightfoot, C., \& Valsiner, J. (1992). Parental belief system under the influence: social guidance of the construction of personal cultures. In: I. E. Siegel, A. V. McGillicuddy-DeLisi \& J. J. Goodnow (Eds.), Parental belief systems (pp. 393-413). Hillsdale: Lawrence Erlbaum.

Lordelo, E., Fonseca, A., \& Araújo, M. (2000). Responsividade do ambiente de desenvolvimento: crenças e práticas como sistema cultural de criação de filhos. Psicologia Reflexão \& Crítica, 13(1), 73-80.

Macarini, S., Martins, G., Sachetti, V., \& Vieira, M. (2010). Etnoteorias parentais: um estudo com mães residentes no interior e na capital de Santa Catarina. Psicologia, Reflexão e Crítica, 23(1), 37-45.

Moinhos, M. Lordelo, E., \& Moura, M. (2007). Metas de socialização das mães baianas de diferentes contextos sócio-econômicos. Revista Brasileira Crescimento Desenvolvimento Humano, 17(1), 114-125.

Parke, R. (1996). Fatherhood. Cambridge: Harvard University Press.

Piovanotti, M. (2007). Metas de socialização infantil $e$ crenças sobre práticas de cuidador parental de mães primíparas. Dissertação de Mestrado em Psicologia apresentada ao Programa de Pós-Graduação em Psicologia na Universidade Federal de Santa Catarina, Florianópolis.

Piccinini, C., Frizzo, G., \& Marin, A. (2007). Interações diádicas e triádicas em famílias com crianças de um ano de idade. In: C. Piccinini., \& M. Seidl de Moura (Eds.). Observando as interações pais-bebê-criança: diferentes abordagens teóricas e metodológicas. (pp. 177-211), São Paulo: Casa do Psicólogo.

Prado, A., Vieira, M., \& Piavanotti, M. (2005). Concepções de mães e pais sobre metas de socialização de filhos. In: D. D. Dell'Aglio (Ed.), Anais do Congresso Brasileiro de Psicologia do Desenvolvimento, Psicologia do desenvolvimento: Teorias, pesquisas e aplicações, 5 (pp. 73). São Paulo: Casa do Psicólogo.

Raj, S., \& Raval, V. (2012). Parenting and family socializations within a cultural context. In: E. L. Anderson \& S. Thomas (Eds.), Socialization: Theories, Processes, and Impact. Hauppauge, NY: Nova Publishers.

Regen, M., Cortez, M., \& Ardore, M. (2001). Conceitos e funções da família. Obtido de <http://www.apabb.org.br/admin/files/Artigos/Conceitos $\% 20 \mathrm{e} \% 20$ Funcoes $\% 20 \mathrm{da} \% 20 \mathrm{Familia}$.pdf $>$ (Acesso em: 08 fev. 2014)

Rogoff, B. (2005). A natureza cultural do desenvolvimento humano. Porto Alegre: Artmed.

Seidl-de-Moura, M., Lordelo, E., Vieira, M., Piccinini, C., Sirqueira, J., Magalhães, C., Pontes, F., Salomão, N., \& Rimoli, A. (2008). Brazilian mothers' socialization goals: Intracultural differences in seven Brazilian cities. International Journal of Behavioral Development, 32(6), 465-472.

Sigel, I., \& Kim, M. (1992). The answer depends on the question. A conceptual and methodological analysis of a parent belief-behavior interview regarding children's learning. In: I. E. Sigel, A. V. McGillicuddy-De Lisi, J. J. \& Goodnow J. J. (Eds.) Parental belief systems: The psychological consequences for children (pp. 83-119). Hillsdale: Lawrence Erlbaum Associates, Publishers.

Silva, M., \& Solis-Ponton, L. (2004). Ser pai e, ser mãe parentalidade: um desafio para o terceiro milênio. São Paulo: Casa do Psicólogo.

Szejer, M., \& Stewart, R. (1997). Nove meses na vida de uma mulher: uma abordagem psicanalítica da gravidez e do nascimento. São Paulo: Casa do Psicólogo.

Tulviste, T. (2013). Socialization values of mothers and fathers: does the child's age matter?. TRAMES: A Journal of the Humanities \& Social Sciences, 17(2), 129-140.

Valsiner, J., \& Van der Veer, R. (2007). Vigotski's word of concepts. In: Valsiner, J. \& Van der Veer, R. (Eds.). The social mind. Cambridge: Cambridge University Press.

Vieira, M., Crepaldi, M., Bossardi, C., Gomes, L., Bolze, S., \& Piccinini, C. (2014). Paternidade no Brasil: revisão sistemática de estudos empíricos. Arquivos Brasileiros de Psicologia, 66(2), 36-52.

Vieira, M., Crepaldi, M., Bossardi, C., Gomes, L., Bolze, S., \& Piccinini, C. (2013). Paternity in the Brazilian Context. In: M. Seidl de Moura (Eds.). Parenting in 

\& Terezinha Féres Carneiro

South American and African Contexts (pp. 17-33). Rijeka: In Techa.

Wilson, S., \& Durbin, C. (2013). Mother-child and fatherchild dyadic interaction: Parental and child bids and responsiveness to each other during early childhood. Merrill-Palmer Quarterly, 59(3), 249-279.

Recebido em: $25 / 03 / 2014$ Primeira decisão editorial em: 18/09/2014 Aceito em: 02/10/2014 